\title{
Cronartium in the Russian Far East
}

Z.M. Azbukina

\begin{abstract}
Additional index words. white pine blister rust, pines, taxonomy, Pinus
F

our species of C ronartium [C. kamtschati cum J oerst., C. ribicola J.C. Fischer, C. flaccidum (Alb. et Schw.) Winter, C. quercuum (Berk.) M ly. ex Shirai], and one species of Peridermium ( $P$. kurilense $D$ ietel) was encountered in the Russian far east. H owever, taxonomic distinctness and biological relationships between $C$. kamtschaticum and C. ribicola, as well as taxonomic status of P. kurilense, have not been studied sufficiently. D uring 1992 to1994, and 1996 to1997, additional rust-infected pines (PinusL.) were collected in several areas of the Russian far east. O bservations of these collections determined that $C$. kamtschaticum is synonymous to $\mathrm{C}$. ribicola. P. kurilense is morphologically and biochemically similar to Endocronartium sanounum mazu et Kakishima var. hokkai doense I mazi et Kakishima. H owever, the taxonomical status of this fungus will be established only after molecular investigation.
\end{abstract}

